\title{
LITERATURE SURVEY ON CEMENTS FOR REMEDIATION OF DEFORMED CASING IN GEOTHERMAL WELLS
}

\author{
M.L. Allan and A.J. Philippacopoulos \\ Department of Applied Science \\ Brookhaven National Laboratory
}

\section{INTRODUCTION}

Brookhaven National Laboratory was requested to conduct a literature survey for the best available cement to use in the proposed casing patch as part of the Geothermal Drilling Organization (GDO) project on remediation of deformed casings. A total of 50 wells has been identified with deformed production casing in Unocal's portion of The Geysers geothermal field. Reduced internal diameter and casing doglegs result in lost production and the possible need for abandonment. The cause of the deformations is believed to be formation movement along fault planes and/or along weaker layers or interfaces between high impedance contrast media. Apparently, it is unclear whether shear or axial compression is the dominant failure mechanism.

A procedure to address the casing deformation and avoid abandonment of these wells has been developed as described in the Geysers Deformed Casing Remediation Proposal. The proposed remediation procedure involves isolation of the zone of interest with an inflatable packer, milling the deformed casing and cementing a 7" diameter liner to extend approximately $100 \mathrm{ft}$ above and $100 \mathrm{ft}$ below the milled zone. During the milling operation it is possible that the original cement and surrounding formation may slough away.

In order to specify a suitable cement formulation for the casing patch it is first necessary to identify and understand the deformation mechanism/s operating in The Geysers field. Subsequently, the required cement mechanical properties to withstand further deformation of the repaired system must be defined. From this information it can be determined whether available cement formulations meet these requirements. In addition to The Geysers, other geothermal fields are at possible risk of casing deformation due to subsidence, seismic activity, lateral and vertical formation movement or other processes. Therefore, the proposed remediation procedure may have applications in other fields.

The literature survey focused on published properties for cements used in geothermal and oil well applications and the experiences of well casing deformation occurring in oil and gas fields. Dr. Mike Bruno of Terralog Technologies kindly supplied a reference list from the DEA (Drilling Engineering Association) 99 Project on Analysis of Well Casing Damage Induced by Reservoir Compaction and Overburden Shear. 


\section{CASING DEFORMATION}

The subject of subsidence in oil and gas fields due to fluid withdrawal and subsequent reduction in pore pressure has been studied extensively. In particular, much information exists on reservoir compaction and subsidence encountered in the Ekofisk gas field in the North Sea and the Wilmington oil field in California. Further details on subsidence, including constitutive and numerical modelling, are described in Chilingarian et al. (1995), Chin et al. (1993), Hamilton et al. (1992) and Bruno and Bovberg (1992).

The mechanisms of casing deformation that occurs in oil and gas fields have been discussed and/or modelled recently by several authors including Hilbert et al. (1996), Fredrich et al., (1996), Schwall and Denney (1994), Veeken et al., (1994), and Bruno (1992). Broadly, these mechanisms include shearing, bending, buckling and collapse due to axial compression, and tension. For example, Schwall and Denney (1994) found axial buckling in the Ekofisk reservoir due to compressive loading and lateral shear deformations in overburden formations to be the primary deformation mechanisms. Which failure mechanism operates depends on several factors including the degree of lateral restraint and the casing location with respect to the compacting reservoir, fault surface or overburden zone. Less information is available on deformation in geothermal wells. Other mechanisms, such as expansion of water trapped in cement voids, can cause casing collapse (Saito, 1994).

Experimental studies on casing deformation in unconsolidated sandstone due to axial compression in compacting reservoirs by Veeken et al. (1994) examined the effects of wellbore deviation, casing thickness and lateral support. The authors suggest that casing deformation is best prevented by sufficient lateral support and this translates to "a good cement job". The mechanical properties of cement meeting this requirement were not investigated in the scope of the paper.

Bruno (1992) considered different well failure mechanisms associated with vertical and horizontal deformations and compared predictions from analytical and numerical models with field observations. This paper notes that shear slip within the casing/cement/formation system will influence axial strains induced by reservoir compaction. Cement damage may occur during compaction due to shear and compressive stresses. Poor bonding between the casing and cement reduces lateral restraint and increases the risk of casing buckling. Shear and bending stresses induced by horizontal deformations are of concern due to the relatively low strength of cement in these modes of loading. The same paper also described overburden shear failure and fault movement induced by subsidence.

Over the last ten years the use of finite element geomechanical models for predicting reservoir compaction and subsidence has intensified. Initial studies with two-dimensional models were extended by applications of three-dimensional modelling of the respective reservoir sites. Several general purpose finite element codes of solid mechanics such as ABAQUS and ADINA or conputer codes based on numerical modelling more specific to geomechanics such as DYNAFLOW have been used in the studies described above. A limited review of a variety of reported studies utilizing such 
models was performed as part of this initial effort on the proposed Geysers deformed casing remediation program. Such review revealed that there is an apparent need to systematically evaluate existing modelling approaches with the objective to selectively apply them to investigations of The Geysers geothermal field. Nonlinear finite element analyses of the Belridge field reported by Hilbert et al. (1996) and Fredrich et al. (1996) using two-dimensional and three-dimensional models respectively are representative of the state-of-the-art analysis of damage in oil wells. The finite element models presented in both studies are very large since the codes used are not strictly for modeling geological media. Modelling infinite geologic media with finite models requires special treatment at the boundaries which otherwise have to be placed at certain distances to avoid potential contamination of the solutions. The latter situation requires additional elements which in turn makes the models very large. Optimizing such models in not a straightforward task. Similar problems have been treated in soil-structure interaction studies where large finite element models have been used to model source-receiver configurations in multi-layered media.

Hilbert et al. (1996) found well-to-well interactions during production in addition to water injection to be responsible contributors for the damage of wells in the Belridge field, California. Moreover, shear deformations were found to be associated with the predominant mode of failure due to well-to-well interactions as well as due to pore compaction and subsidence. Material behavior of the relevant geologic media was modeled by multi-surface plasticity models. It is proposed that additional consideration be given to long term deformations due to creep as well as to the coupling between pore fluid and skeletal material of the porous media. Fredrich et al. (1996) compute the reservoir pressure time histories by finite difference and then use them as input to a 3D finite element model from which stresses and deformations are obtained. Again, the coupling between the solid and fluid phases was neglected. Such action can be taken into account in the response computation by using coupled material models. Some codes as DYNAFLOW seem to have incorporated such coupled models. Similarly, Brookhaven has developed the POROSLAM code which handles coupled behavior. The magnitude of the influence of such coupling for the type of problems considered by the remediation of geothermal wells needs to be addressed.

While large finite element techniques have been used to treat the site problem in oil fields, some analytical techniques were also proposed to analyze local modes of deformation in oil wells. In the study by Thiercelin et al. (1997) simplified models incorporating the well casing, cement and surrounding rock have been employed. Solutions using fundamental thermoelastic analysis provide the stress field assuming welded or relaxed type interface conditions (casing-cement and cement-rock interfaces). Having defined the stress field, the effort is then concentrated in defining optimum cement mechanical properties. What makes this study interesting is that the models used are very simple thus allowing for analytic solutions. It is recommended that a similar approach be considered in the evaluation of the casing patch for The Geysers remediation program. This task will provide some useful insights with respect to the cement stresses in the linear range. Such a task, however, should be supplemented with nonlinear stress analysis that can be carried out using finite element models representing the local behavior of the geothermal wells. 
Brookhaven has developed a variety of cements for geothermal energy applications. This background can be utilized to develop a specific cement to be used in the proposed casing patch for The Geysers deformed casing remediation program. It is understood that in developing a cement for the casing patch, one must consider material behavior in the failure mode range. Stresses, both in magnitude as well as type, are beyond those encountered in ordinary strength designs. Based on what it has been reported thus far from related casing damage problems by the oil industry, it is concluded that cracking and debonding of the cement occurs due to a combination of stresses and deformations, the definition of which is typically unknown. Therefore, it is reasonable to expect that a systematic effort be spent in analyzing the stress field in the vicinity of the damaged wells. This will lead to a better understanding of the cement material strength requirements. Materials currently used in geothermal applications can be subsequently enhanced to meet such strength requirements.

A two-step approach is recommended:

In the first step, the interest must be concentrated on the prediction of the site response of the geothermal field due to a variety of loading conditions such as those related to field operations, movements due to tectonic forces or other long or short term site-specific deformations.

The second step should focus on the local problem which involves the analysis/design of the casing remediation in view of the potential failure modes which were identified during the site response investigations.

Solving the site response problem requires the definition of the stress and deformation fields at any point of interest throughout the site (usually in the reservoir and overburden). Accordingly, the overall mechanism responsible for unwanted deformations in geothermal wells can be identified in terms of forces and displacements. Correlation of measured data with modelling results from site response analysis using finite element models have been reported by several studies of reservoir compaction and surface subsidence in oil and gas fields. Typically, such correlations are at the level of deformation patterns. The main reason is that standard field measurements involve displacements rather than in situ stresses. With very few exceptions, a typical conclusion reached by most of the studies reviewed in this report is that the results of the model matched with good accuracy the subsidence bowl. Knowledge of the stress field is very important in evaluating failure modes of geothermal wells and the soundness of the proposed remediation strategies. Therefore, a monitoring program considering measurements of the stress field is recommended for geothermal fields considered for casing remediation. Stress or strain time histories from computer code predictions need to be correlated with the corresponding site-specific values obtained from such a monitoring program. Some threshold stress values should also be formulated so that the data from the monitoring program can be evaluated by a direct comparison. 


\section{GEOTHERMAL WELL CEMENT PROPERTIES}

Cements used for completion of geothermal wells are designed to withstand higher temperatures and more aggressive environments than those encountered in oil and gas wells. In addition to meeting requirements for pumpability, the cements must be durable in high temperature brines and resist carbonation. It is typical to use API Class G cement with selected additives to control properties such as rheology, density, set time and durability. Therefore, the literature survey focused on this cement. Silica flour is used to prevent strength retrogression and latex imparts chemical resistance and prevents gas migration. Accelerators and retarders are used to control set time. Density can be manipulated by addition of extenders or weighting agents. Microspheres or nitrogen are suitable for density reduction. Rheological properties can be improved by the use of dispersants. In situations where permeable formations are encountered it may be necessary to use fluid loss additives.

The majority of reviewed mechanical property data for geothermal and oil well cements was limited to unconfined compressive strength. The published property data also tends to neglect inherent statistical variability of the data. The compressive strength depends on the mix formulation, density, curing conditions and age. Specimen size and strain rate during testing can also influence the measured value of strength. A minimum compressive strength at 24 hours of $6.9 \mathrm{MPa}(1000 \mathrm{psi})$ is usually specified and should be maintained for at least 12 months (API, 1985). With regard to cement bond strength to steel, a minimum value of $0.69 \mathrm{MPa}$ (100 psi) is required (Nelson, 1980).

Gallus, Pyle and Watters (1978) monitored for the compressive strengths of Class $G$ and Class J cements exposed in geothermal wells in Baca, New Mexico and Imperial Valley, California Valley up to 12 months. The effects of water/cement ratio, silica flour, silica sand, perlite and fly ash were investigated. Highest strengths were obtained with mixes containing silica sand. Addition of $40 \%$ silica flour resulted in fairly stable strength between 20.7 and $27.6 \mathrm{MPa}$ (3000 and $4000 \mathrm{psi}$ ) with exposure time after three months. Addition of silica to Class $\mathrm{G}$ cement resulted in similar performance to Class J without added silica. Mixes containing perlite and silica flour had strengths below 13.8 MPa (2000 psi). Strength of these formulations varied with exposure time and environment. The effect of fly ash on the Class $\mathrm{G}$ cement strength was variable.

Nelson (1980) investigated the compressive and bond strengths of Classes B, G, J, calcium aluminate and other cements. The impact of different additives including silica flour, perlite, bentonite, diatomaceous earth and retarders was studied. Specimens for compressive strength tests were cured at 227 and $316^{\circ} \mathrm{C}$. The 28 day strengths of mixes based on Class $\mathrm{G}$ with 20 to $35 \%$ silica flour ranged from 4.4 to $55 \mathrm{MPa}$ ( 640 to $7950 \mathrm{psi}$ ). Higher strengths were usually obtained at the higher curing temperature. Compressive strength of various cements after exposure to recirculating synthetic brine at $350^{\circ} \mathrm{C}$ for up to 15 months was also measured. Strength retrogression was observed for the Class G-silica flour mixes although some retained compressive strength above 6.9 $\mathrm{MPa}$ (1000 psi). Bond strengths to the inner and outer surface of steel pipe were measured on specimens cured in water at $204^{\circ} \mathrm{C}$ for 28 days. The external bond strengths for Class G-silica flour 
mixes ranged from 1.0 to $5.9 \mathrm{MPa}$ (150 to $850 \mathrm{psi}$ ). The internal bond strengths ranged from 3.6 to $17.2 \mathrm{MPa}$ ( 525 to $2550 \mathrm{psi}$ ). Further information on the different cements tested can be found in Nelson's report.

Compressive strength data at 7,30 and 90 days for Class $G$ cements for different silica flour contents and other additives that were cured in carbonated brine at $273^{\circ} \mathrm{C}$ are summarized by Schlumberger Dowell (1993). The 7 day strengths ranged from 2.9 to $48.3 \mathrm{MPa}$ (421 to $7009 \mathrm{psi}$ ). Compressive strengths of Class $\mathrm{G}$ mixes containing 35\% silica flour and having different densities are given in API Worldwide Cementing Practices (1991). The values typically lay between 6.9 and $20.7 \mathrm{MPa}$ (1000 and $3000 \mathrm{psi}$ ) for densities ranging from 9 to $12 \mathrm{lb} . / \mathrm{gal}$ and a curing time of one month.

Berra et al. (1988) presented compressive strength and elastic modulus results for Geoterm cement which is produced by intergrinding Class $\mathrm{G}$ cement, silica and natural gypsum. The slurry also contained retarder and antifoam. The effects of curing time (1 to 28 days) and curing temperature $\left(20\right.$ to $426^{\circ} \mathrm{C}$ ) were measured. The specimens were cured in demineralized water. After 28 days of curing the compressive strengths ranged from 24.8 to $88.6 \mathrm{MPa}$ (3600 to $12900 \mathrm{psi}$ ). The highest values occurred at curing temperatures of 127 and $149^{\circ} \mathrm{C}$. The 28 day modulus of elasticity was also dependent on curing temperature and ranged from $767 \mathrm{MPa}\left(111 \times 10^{3} \mathrm{psi}\right)$ at $20^{\circ} \mathrm{C}$ to $14736 \mathrm{MPa}$ $\left(2139 \times 10^{3} \mathrm{psi}\right)$ at $149^{\circ} \mathrm{C}$.

Foam cements have been reported to perform well in the Williston Basin where salt movement can result in casing collapse (Bour and Vennes, 1989). This was attributed to better mud removal and better cement completion. The formulation was based on Class $G$ cement and used nitrogen to create the foam. Compressive strength data for different cement densities, curing time and curing temperature were presented. At 72 hours the compressive strengths ranged from 0.96 $\mathrm{MPa}(140 \mathrm{psi})$ for $18^{\circ} \mathrm{C}$ and $6 \mathrm{lb} . / \mathrm{gal}$ to $16.9 \mathrm{MPa}(2450 \mathrm{psi})$ for $60^{\circ} \mathrm{C}$ and $12.5 \mathrm{lb} . / \mathrm{gal}$. Morris et al. (1989) used anionic aromatic polymers to improve cement bonding for use in the Williston Basin. The compressive strength of a polymer modified Class $\mathrm{G} / \mathrm{Silica}$ Flour $/ \mathrm{NaCl}$ system was found to be similar to a Class $\mathrm{H}$ system. The 24 hour compressive strengths were 20.6 and $20.7 \mathrm{MPa}$ (2990 and 3000 psi), respectively.

In addition to enhancement of chemical resistance, bonding and impermeability, latex reduces the modulus of elasticity of cement formulations and increases flexural strength. Ohama (1985) describes the impact of latex on Portland cement-based materials. Fibre reinforcement is another means of improving flexural strength of cementitious materials. Paftis (1995) has investigated the flexural properties of Class $G$ fibre reinforced oil well cement modified with latex. The fibres were glass and the latex was styrene butadiene. The flexural strength of different formulations was measured at 72 hours. The control mix (no latex, no fibres) had a mean flexural strength of $47 \mathrm{MPa}$ (6820 psi). Addition of fibres increased the mean flexural strength to $62 \mathrm{MPa}$ (9000 psi) and addition of both fibres and latex resulted in a mean strength of $73 \mathrm{MPa}(10600 \mathrm{psi})$. These values appear to be very high compared with Portland cement-based materials. 
Terralog Technologies (1997) has conducted triaxial compression and extension tests on Class G cement with two different densities and examined constitutive models to describe failure. The tests showed the dependence of mechanical properties on confining pressure. The data in this report are confidential.

Another factor that needs to be considered is the effect of temperature on the cement properties. Most property data are measured at room temperature, even if the specimens are cured at higher temperatures, and this does not necessarily reflect the behaviour at elevated temperatures encountered in a geothermal well. For Portland cement-based concrete the compressive strength, flexural strength, Poisson's ratio and modulus of elasticity tend to decrease with increasing temperature (Kaplan and Roux, 1972; Marechal, 1972).

The response of cement to downhole pressure and temperature has been analyzed by Thiercelin et al. (1997). Radial and tangential stresses were calculated for changes in wellbore pressure and temperature and the effects of cement and formation elastic modulus investigated. The requirements for cement tensile strength and elastic modulus depend on the expected loading and formation properties. Hence, under certain conditions low modulus cement may be advantageous. This is in addition to other requirements such as durability, permeability and bond strength. Although the reported work did not consider the type of well casing deformation presumed to be occurring at The Geysers, the principle that the cement properties can be tailored to prevent damage due to induced stresses remains applicable.

Brookhaven National Laboratory has recently performed research on calcium phosphate cements that are resistant to degradation by $\mathrm{CO}_{2}$ and corrosive brines. These cements are produced by reacting calcium aluminate (high alumina) cement with phosphates or polyphosphates and can be modified with fly ash, blast furnace slag, retarders, extenders etc. to control the properties. The calcium phosphate cements have recently been used in Indonesia to deal with severe environments (Weber et al., 1998). The research has focused primarily on pumpability, carbonation resistance, permeability and durability in brines at high temperature and pressures. Unconfined compressive strength has been used to monitor changes with time of exposure. The calcium phosphate cement has a shear bond strength to steel of $0.75 \mathrm{MPa}$ (109 psi) compared with $1.65 \mathrm{MPa}$ (239 psi) for Class G cement (Kukacka and Sugama, 1995). Calcium phosphates have been studied for use in lost circulation control (Allan and Kukacka, 1995). Brookhaven has also investigated polymer concretes based on organosiloxanes and other materials for geothermal well completion (Zeldin et al., 1981). 


\section{RECOMMENDATIONS}

Specification of a particular cement formulation for use in the proposed well casing remediation strategy at The Geysers is restricted to qualitative terms at this stage due to urcertainties in the deformation mechanism/s and the magnitude and orientation of induced stresses. In order to have a meaningful definition of cement for the proposed casing patch a two-step approach is recommended. In the first step, the effort should be devoted towards obtaining an adequate description of the stress and deformation regime at the site. This will allow us to define the overall mechanisms that drive the deformations that ultimately result in damage of the geothermal wells. The second step would then be devoted to the evaluation of the local failure modes and consequently specify the strength requirements of the proposed cement patch. In both steps, various analytical tasks need to be performed with different levels of accuracy and sophistication. This will put us in a better position to develop design criteria appropriate for the lifetime of the cement patch.

Constitutive models to describe mechanical behaviour of candidate cements under multiaxial loads at elevated temperatures, experimental material and associated statistical pararneters are required for accurate prediction of system response. Such information for geothermal cements is sparse in the open literature. The impact of patch length on response to expected loads should also be analyzed to fully optimize the repair design. Other stresses induced by operational thermal and pressure cycles need to be taken into account. Experimental simulation should be performed to reproduce the expected modes of failure and to test the patch cements. Another recommendation is that the remediated well casing patch be instrumented to monitor in-situ performance in terms of deformation and bonding. Knowledge of deformation mechanism/s, combined with analytical and numerical methodologies and material parameters will facilitate selection of the best cement to prevent deformation of the repair liner.

In the interim, the proposed remediation could proceed using an available cement which has the required ease of placement, economics and durability in addition to good compressive and flexural strength, shear bond to steel, toughness, and ductility at elevated temperatures. Use of a Class G mix that contains silica flour and latex would enable proof-of-concept testing of the proposed remediation strategy. Addition of latex will improve ductility and bonding to steel. Fibre reinforcement may be beneficial based on the expected increase in toughness and improved flexural and tensile properties. Foam cements may be worthy of consideration if strength criteria at temperatures of interest can be demonstrated.

Calcium phosphate cements under research at Brookhaven need more detailed characterization of mechanical properties relevant to the remediation system before making any recommendations. Without this quantitative data the performance can only be speculated. The excellent high temperature and carbonation resistance of these cements makes them useful in high $\mathrm{CO}_{2}$ environments and potentially suitable for patching deformed casings if the mechanical properties and economics are suitable. 


\section{ACKNOWLEDGEMENTS}

This work was performed under the auspices of the U.S. Department of Energy under Contract No. DE-AC02-98CH10886. Thanks are due to Dr. Allan Sattler of Sandia National Laboratories for the opportunity to conduct the survey and for his assistance.

\section{REFERENCES}

M.L. Allan and L.E. Kukacka, Calcium Phosphate Cements for Lost Circulation Control in Geothermal Drilling, Geothermics, V. 24, No. 2, pp. 269-282, 1995.

API Task Group on Cements for Geothermal Wells, API Work Group Reports Field Tests of Geothermal Cements, Oil and Gas Journal, February 11, pp. 93-97, 1985.

API, Worldwide Cementing Practices, American Petroleum Institute, Washington, D.C., First Edition, 1991.

M. Berra, F. Fabbri, M. Facoetti, A. Noris, M. Pezzuoli, R. Ricciardulli, G. Romano and B. Tarquini, Behaviour of a Cementing Hydraulic Binder Under Severe Geothermal Conditions, Geothermics, V. 17, No. 5/6, pp. 785-813, 1988.

D.L. Bour and M.R. Vennes, Application of Foam Cement in Williston Basin, SPE 18984, 1989.

M.S. Bruno, Subsidence-Induced Well Failure, SPE Drilling and Engineering, pp. 148-152, 1992.

M.S. Bruno and C.A. Bovberg, Reservoir Compaction and Surface Subsidence Above the Lost Hills Field, California, in Rock Mechanics, Tillerson and Wawersik (eds), Balkema, Rotterdam, pp. 263$272,1992$.

G.V. Chilingarian, E.C. Donaldson and T.F. Yen (eds.), Subsidence Due to Fluid Withdrawal, Developments in Petroleum Science, 41, Elsevier Science, 1995.

L. Chin, R.R. Boade, J.H. Prevost and G.H. Landa, Numerical Simulation of Shear-Induced Compaction in the Ekofisk Reservoir, International Journal of Rock Mechanics, Mining Science and Geomechanics Abstracts, V. 30, No. 7, pp.1193-1200, 1993.

J.T. Fredrich, J.G. Argüello, B.J. Thorne and W.R. Wawersik, Three-Dimensional Geomechanical Simulation of Reservoir Compaction and Implications for Well Failures in the Belridge Diatomite, SPE 36698, 1996.

J.P. Gallus, D.E. Pyle and L.T. Watters, Performance of Oil Well Cementing Compositions in Geothermal Wells, SPE 7591, 1978. 
J.M. Hamilton, A.V. Maller and M.D. Prins, Subsidence-Induced Shear Failures Above Oil and Gas Reservoirs, in Rock Mechanics, Tillerson and Wawersik (eds), Balkema, Rotterdam, pp. 273-282, 1992.

L.B. Hilbert, J.T. Fredrich, M.S. Bruno, G.L. Deitrick and E.P. Rouffignac, Two-Dimensional Nonlinear Finite Element Analysis of Well Damage due to Reservoir Compaction, Well-to-Well Interactions, and Localization on Weak Layers, in Rock Mechanics, Aubertin, Hassani and Mitri (eds), Balkema, Rotterdam, pp. 1863-1870, 1996.

M.F. Kaplan and F.J.P. Roux, Effects of Elevated Temperatures on the Properties of Concrete for the Containment and Shielding of Nuclear Reactors, in ACI SP 34, American Concrete Institute, Detroit, pp. 437-442, 1972.

L.E. Kukacka and T. Sugama, Lightweight $\mathrm{CO}_{2}$-Resistant Cements for Geothermal Well Completions, Proceedings of the World Geothermal Congress, Florence, 18-31 May, pp. 1439-1444, 1995.

J.C. Marechal, Variations in the Modulus of Elasticity and Poisson's Ratio with Temperature, in ACI SP 34, American Concrete Institute, Detroit, pp. 495-504, 1972.

B.V. Morris, E.F. Shumaker and L.K. Ramsey, New Cement System Improves Bonding in the Stony Creek Field, Williston Basin, North Dakota, SPE 18985, 1989.

E.B. Nelson, Development of Geothermal Well Completion Systems, Dow Chemical, Report COO/4190-9, 1980.

Y. Ohama, Polymer-Modified Mortars and Concretes, in Concrete Admixtures, V.S. Ramachandran (ed.), Noyes Publications, Park Ridge, pp. 337-429, 1984.

D.G. Paftis, Improving the Flexural Strength of Fibre Reinforced Oil Well Cements by Addition of a Polymer Latex, Materials Research Society Symposium Proceedings, Volume 370, pp. 565-571, 1995.

S. Saito, A New Advanced Method for Top-Job Casing Cementing, Geothermal Resources Council Transactions, V. 18, pp. 99-103, 1994.

Schlumberger Dowell, Geothermal Cementing, 1993.

G.H. Schwall and C.A. Denney, Subsidence Induced Casing Deformation Mechanisms in the Ekofisk Field, Eurock ‘94, Balkema, Rotterdam, pp. 507-515, 1994. 
Terralog Technologies, DEA Phase II Report: Cement Influences on Casing Collapse, Submitted to DEA 99 Project Sponsors, July 25, 1997.

M.J. Thiercelin, B. Dargaud and J.F. Baret, Cement Design Based on Cement Mechanical Response, SPE 38598, 1997.

C.A.M. Veeken, J.P. Wahleitner and C.R. Keedy, Experimental Modelling of Casing Deformation in a Compacting Reservoir, Eurock '94, Balkema, Rotterdam, pp. 497-506, 1994

L. Weber, E. Emerson, K. Harris and L. Brothers, The Applications of a New Corrosion Resistant Cement in Geothermal Wells, Geothermal Resources Council Transactions, V. 22, pp. 25-30, 1998.

A.N. Zeldin, L.E. Kukacka and N. Carciello, New, Novel Well-Cementing Polymer Concrete Composite, ACI SP-69, American Concrete Institute, Detroit, pp. 73-92, 1981. 
